\title{
Differences in the Behavior of Attached and Floating Cells Subjected to Low Intensity Ultrasound
}

\author{
Mariantonietta Ivone and Carmine Pappalettere \\ Department of Mechanical and Management Engineering, Politecnico di Bari, Italy \\ Email: \{mariantonietta.ivone, carmine.pappalettere\}@poliba.it \\ Katsuro Tachibana \\ Department of Anatomy, Fukuoka University, School of Medicine, 7-45-1 Nanakuma, Fukuoka 814-0180, Japan \\ Email: sonodynamics@me.com
}

\begin{abstract}
Through mechanical considerations, we will try to determine whether cancer cells die because of resonance or energy present in solution. Attached and floating cells were stressed at fixed frequencies in a range between $400 \mathrm{kHz}$ and $620 \mathrm{kHz}$ at 10 PRF (Pulse Repetition Frequency). In the floating cells the power and the mortality show similar variations with respect to frequency and this allows to assume a direct relationship between power and mortality. The same experiment was replicated on attached cells by exposing the cultures at US of fixed frequency (between 400 and $620 \mathrm{kHz}$, with $10 \mathrm{~Hz}$ Pulses Repetition Frequency) either keeping constant power output or voltage. Cell mortality was found to be more sensitive to the frequency.
\end{abstract}

Index Terms - attached cells, floating cells, stiffness, amplitude, frequency

\section{INTRODUCTION}

The purpose of this experiment is the comprehension of the mechanism of action of ultrasonic perturbation on cancer cell mortality. Which one is more effective, amplitude or frequency on cell survival? Does the cell die due to resonance or for a biomechanical response linked to the stress? There are evidences that low intensity ultrasound changes the mechanical property of some cancer cell [1], [2] and that can interfere with the expression of the major cytoskeletal elements [3-5] and specific integrin-binding proteins of these cells. It is known that the hyper proliferation of cancer cells is stopped by sonication [6]-[10]. In the same way, selectivity of ultrasounds is recognized: as they can destroy cancer cells preserving healthy cells [11], they are considered one of the most harmless diagnostic and treatment resources.

This study will evaluate cell mortality induced by different sonication conditions on floating (U937) and attached cancer cells (MCF-7).

Frequency and intensity have an important role in cell fate in relation to its size and mechanical characteristics

Manuscript received July 7, 2016; revised January 12, 2017.
[12]. In this regard, it should be specified that cell cultures, both floating and attached cells, show a high heterogeneity in cell sizes.

\section{MATERIAL AND METHODS}

\section{A. Ultrasound Apparatus and Intensity Measurement}

The ultrasound generating apparatus is SonoPore KTAC-4000, (Nepa-Gene, Chiba, Japan). The KTAC equipment can generate frequencies from $200 \mathrm{kHz}$ to $5000 \mathrm{kHz}$ with a fine adjustment of $1 \mathrm{kHz}$. The probe used in the experiments is the diameter $20 \mathrm{~mm} \mathrm{KP}-\mathrm{S} 20$ (Nepa-Gene, Chiba, Japan). The instrument allows to select voltage. One of the problems related to the use of ultrasonic generators is the measure of the output power. At the same voltage during changing frequency, the power output varies in real time. The power reading is displayed during the treatment. But this measure is only indicative as it derives the power from the measurement of electrical intensity. In addition, each probe is characterized by a different output, even for the same nominal power value.

Probe output was calibrated in the range $400 \mathrm{kHz}-620$ $\mathrm{kHz}$, first by means of radiation force balance (Mettler Toledo, NewClassic MS, S/N B047090420). Power was measured and acoustic pressure was then sensed by a fiber optic hydrophone (Precision Acoustics, Dorset, UK).

\section{B. Cell Culture and US Treatment}

The U937 cell line is an oncogenic human monocyte cell line. They were isolated from the histiocytic lymphoma of a 37-year-old male patient. The interest in these cells is not related to behavior and differentiation of monocyte, but to U937 carcinogenicity and at their characteristic to be floating cells. Their behavior is counteracted at that of MCF-7, a breast cancer cell line isolated in 1970 from a 69-year-old Caucasian woman (Fig. 1).

It has high metastatic potential, invasiveness and carcinogenicity and is attached cell line. 


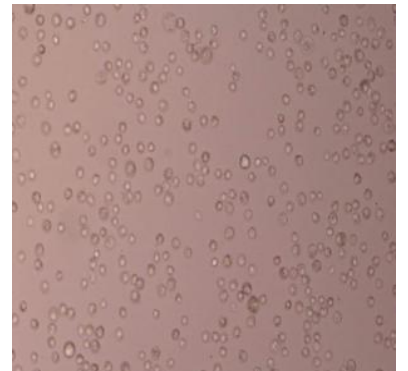

U937

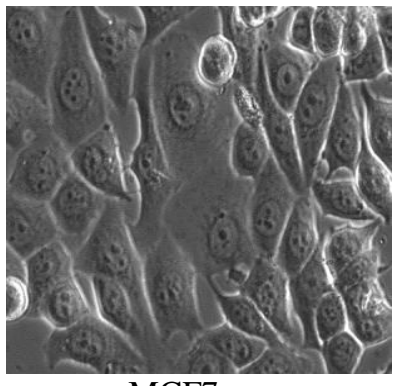

MCF7
Figure 1. Cell lines used in experiment.

The human myelomonocytic lymphoma cell line U937 was cultured in RPMI 1640 (Sigma-Aldrich, MO, USA) supplemented with $10 \%$ heat-inactivated fetal bovine serum 10\% (FBS; Sigma-Aldrich, MO, USA) at $37.0^{\circ} \mathrm{C}$ in humidified air with $5 \% \mathrm{CO}_{2}$. On the day of experiment, cells were collected and centrifuged at $1500 \mathrm{rpm}$ for 5 min. The viability before treatment was always higher than $95 \%$.

Cells were then resuspended in fresh medium at a final concentration of $10^{6}$ cells $/ \mathrm{ml}$ and $2 \mathrm{ml}$ were aliquoted in each well of Lumox Multiwell 24 TC Quality (GreinerBio). The dishes were sonicated at PRF (Pulse repetition frequency) $10 \mathrm{~Hz}$, DC (duty cycle) $50 \%$, at fixed frequencies $400 \mathrm{kHz}, 436 \mathrm{kHz}, 472 \mathrm{kHz}, 510 \mathrm{KHz}, 546$ $\mathrm{kHz}, 582 \mathrm{kHz}, 620 \mathrm{kHz}$ for $180 \mathrm{~s}$. The low values of power recorded during the experiment and the value of intensity recorded in the probe calibration phase let us presume to be below inertial cavitation threshold. The cells were subjected to sonication in pulsed wave, with duration 180 seconds, and at $60 \mathrm{~V}$. Cell viability was immediately assessed after sonication by means of Trypan blue dye exclusion test. Cell suspension containing $10 \mu \mathrm{l}$ was mixed with an equal volume of $0.4 \%$ Trypan Blue solution. After mixing, $10 \mu \mathrm{l}$ of solution were pipetted in a counting slide and introduced in TC20 $20^{\mathrm{TM}}$ Automated Cell Counter (Bio-rad, USA). The number of total and alive cells were displayed immediately on the monitor.

The attached cells culture is human breast adenocarcinoma cell line MCF-7. MCF-7 cells were grown in plastic T-75 flasks (Sigma-Aldrich). They were cultured in RPMI 1640 (Gibco Termofisher, USA) supplemented with $10 \%$ heat-inactivated fetal bovine serum (FBS; Sigma-Aldrich, MO, USA) at $37^{\circ} \mathrm{C}$ in humidified air with $5 \% \mathrm{CO}_{2}$.

Cell viability was assessed after sonication by means of Trypan blue dye exclusion test on a macroscopic sample, to know at macroscopic level the effect of intensity and frequency.

For this test, the cells were cultured in $35 \mathrm{~mm}$ diameter Petri dish the day before the experiment. The cells confluence before the experiment was almost $90 \%$. After different sonication protocols, cells in the dish were immediately washed with PBS (Phosphate-buffered saline), detached from the dish bottom by $0.250 \mathrm{ml}$ $0.05 \%$ Trypsine for $3 \mathrm{~min}$, added $1,75 \mathrm{ml}$ medium, mixed, added again old supernatant, PBS and Trypan Blue centrifuged for $3 \mathrm{~min}$ at $1200 \mathrm{rpm}$ and counted by Luna count cell (Logos Biosystem).

The same procedure was also performed on the nonsonicated cells of controls dish.

In the second experiment (probe characterization by viability), cells were sonicated introducing the probe in the dish in touch with solution by a support that kept the probe always in the same liquid relative position.

The sonication condition for this treatment were the following: sinusoidal wave in PW (pulsed wave), $10 \mathrm{~Hz}$ PRF 50\%, DC at the fixed frequencies of $400 \mathrm{kHz}, 436$ $\mathrm{kHz}, 472 \mathrm{kHz}, 510 \mathrm{KHz}, 546 \mathrm{kHz}, 582 \mathrm{kHz}, 620 \mathrm{kHz}$. The tests were conducted once at the constant voltage of $60 \mathrm{~V}$ and once maintaining constant power of $0.1 \mathrm{~W}$. In the latter case, voltage values (set to have $0.1 \mathrm{~W}$ output on the KTAC) were:

\begin{tabular}{|c|c|}
\hline Frequency & Voltage \\
\hline 400 & 75 \\
\hline 436 & 66 \\
\hline 472 & 81 \\
\hline 510 & 61 \\
\hline 546 & 56 \\
\hline 582 & 51 \\
\hline 620 & 42 \\
\hline
\end{tabular}

\section{RESULTS AND DISCUSSIONS}

In the U937 experiment, cell killing rate was determined as the ratio of the difference between average number of alive cells of the day control (non-ultrasound treated cells assumed to have $100 \%$ viability) and average number of alive cells after sonication, to the number of control cells.

Killing rate was related to the probe output, calibrated by means of an oscilloscope in series with a KP-S20 probe used as a microphone, connected to probe to characterize.

For AC measures, the root mean squared signal $\left(\mathrm{V}_{\mathrm{RMS}}\right)$ is proportional to the power of the signal. The conversion factor was experimentally determined between the obtained data and the data in $\mathrm{W}$ by a radiation force balance with suspended target (Mettler Toledo, NewClassic MS).

The results showed a direct relation between killing rate and power (Fig. 2).

This lets us assume that, in this case, the intensity and hence the amplitude had a greater role than frequency in the cell mortality.

The investigation was continued on attached cells. The viability test was performed at constant voltage $(60 \mathrm{~V})$ and at constant power $(0.1 \mathrm{~kW})$.

Due to the different type of cells, in this experiment mortality (the complement to one of the viability) was compared with the power. The attached cells, although resulting from the same crop, bred overnight with speeds slightly different and could not be compared with the non-sonicated control. 


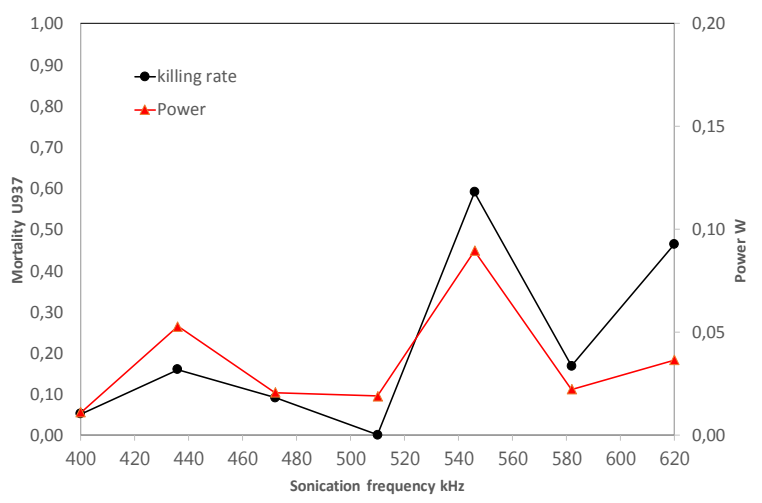

Figure 2. U937 killing rate and probe output at fixed frequencies.

The probe calibration gave results a little bit different due to the different probe used and the dependence by power was not so evident as shown in Fig. 3. The frequency seems to affect mortality much more significantly (see Fig. 4).

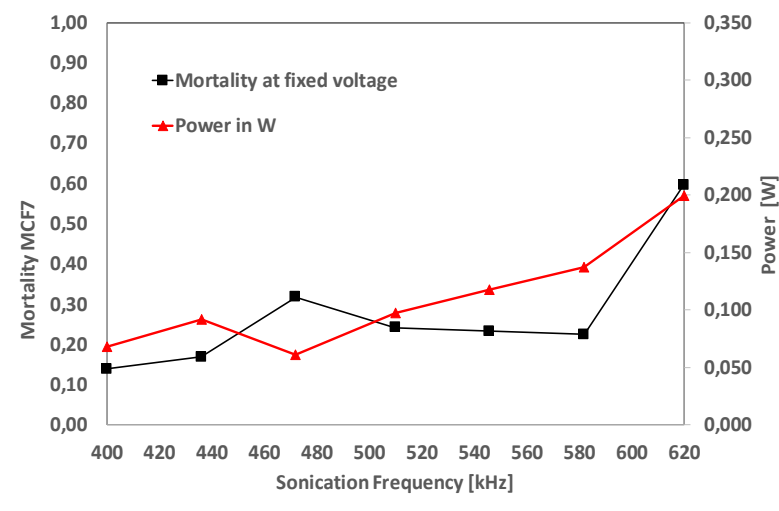

Figure 3. MCF7 mortality at fixed voltage and probe output at fixed frequencies.

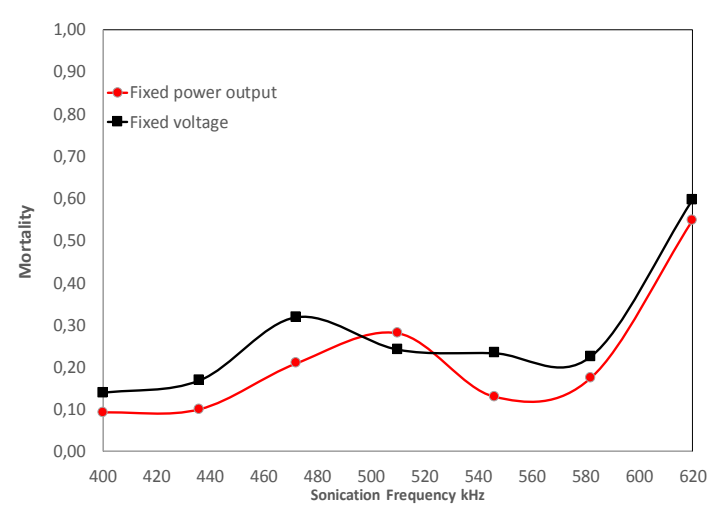

Figure 4. Mortality at fixed power output and at fixed voltage.

The frequency had a strong influence on the diameter. Regardless of the sonication protocol adopted in the experiments, cell diameter always was found to decrease with frequency and this trend became more marked at the very high frequencies, as shown in Fig. 5. Probably, since adhered cells are somehow similar to semi-ellipsoids, it will be easier to put into vibration bigger cells along some preferential direction and cause early mortality for resonance.

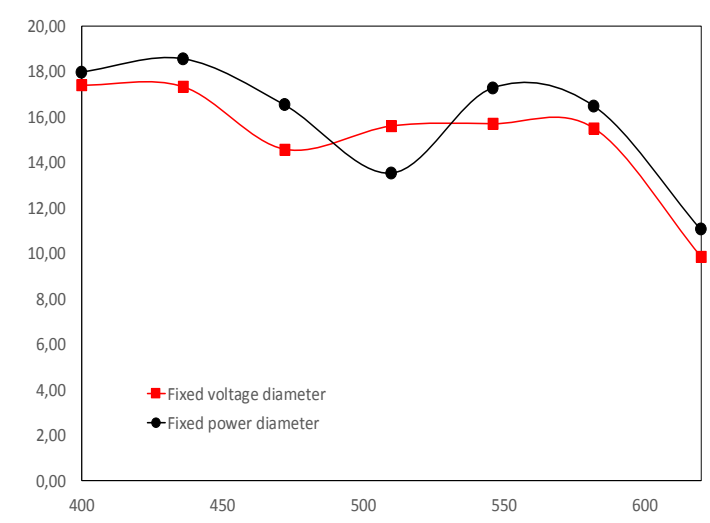

Figure 5. Diameter at $60 \mathrm{~V}$ fixed voltage (square) and diameter at $0.1 \mathrm{~W}$ fixed power (circle).

It is really difficult to hypothesize a different mechanism of death for these cells. What we can see is that in the first experiment, the medium in which are suspended the U937 cells has a mass, a rigidity, an elasticity and a thermal inertia. So the solution absorbs power from probes and gives back it to cells. Therefore, in this case, the cells are more sensitive to power.

In the second experiment, cells were constrained to the substrate and to the neighboring cells. These kinematic constrains do not allow each cell to displace independently of the other cells and the whole culture starts to vibrate simultaneously.

\section{CONCLUSIONS AND FUTURE DiRECTIONS}

The present results suggest that the synergistic action of intensity and frequency induces mortality.

Each biological process is influenced by the mechanical properties of the surrounding environment: mechanical cues play an integral role in maintaining and influencing the cell fate and tissue maintenance throughout life.

The investigation is still in its infancy. In the next future it would be interesting to deepen the correlation between dimensional and mechanical property like size and cell stiffness. For which it would be necessary to repeat the experiments on different types of cells with different geometries and mechanic features. It would allow us to determine an empirical relationship between the type of cells and the best conditions of sonication to destroy them.

In particular healthy cells (platelet-rich plasma, erythrocytes, monocytes) will be tested: our sonication parameters are commonly used in different medical applications, like in physiotherapy, in lithotripsy and in aesthetic cavitation, therefore a destructive effect on healthy blood cells can be ruled out, but it need other confirms.

It seems that the floating cells behavior is different from attached cells behavior: in the first ones amplitude effect is dominant, in second ones the frequency is prevailing on mortality and cell diameter. In future constant power tests will also be performed on floating 
cells, they will provide better information about the correlation between size and frequency

\section{ACKNOWLEDGMENT}

The authors are deeply indebted to the members of Prof. Tachibana's research group at the Fukuoka University Department of Anatomy for their help in the experimental work entailed by this study. The authors wish to thank Dr. Pamela Robertson for her assistance in MCF-7 cell culture and viability tests and the Prof. Paul Campbell to Prof. Irwin McLean for having granted access to the facilities in his laboratory settled in the Life Sciences school of Dundee University.

\section{REFERENCES}

[1] M. Conneely, D. McGloin, P. Robertson, W. H. I. McLea, and P. A. Campbell, "Influence of ultrasound exposure on cellmechanical properties: A preliminary study on MCF7 human breast cancer cells," in Proc. 15th European Microscopy Congress, Manchester, 2012.

[2] M. Conneely, D. McGloin, P. Robertson, W. H. I. McLean, and P. A. Campbell, "A nano-mechanical study on the influence of ultrasound exposure on cellular elasticity," in Proc. IEEE International Ultrasonics Symposium (IUS), 2013, pp. 390-392.

[3] M. C. 1. Meazzini, C. D. Toma, J. L. Schaffer, M. L. Gray, and L. C. Gerstenfeld, "Osteoblast cytoskeletal modulation in response to mechanical strain in vitro," J. Orthop Res., vol. 16, no. 2, pp. 17080, March 1998

[4] Y. Furusawa, et al., "DNA double-strand breaks induced by cavitational mechanical effects of ultrasound in cancer cell lines," PLoS One, vol. 7, no. 1, pp. 1-8, January 2012.

[5] E. Mfoumou, S. Narayanswamy, I. Stiharu, and A. L. Moustafa, "A low power ultrasound inhibits cell proliferation and invasion of human cancer cells in vitro," Clinical Cancer Investigation Journal, vol. 1- 2, pp. 51-56, 2012.

[6] I. Hrazdira, J. Škorpíková, and M. Dolníková, "Ultrasonically induced alterations of cultured tumour cells," European Journal of Ultrasound, vol. 8, no. 1, pp. 43-49, September 1998.

[7] A. Watanabe, H. Nishimura, N. Kawashima, and S. Takeuchi, "Consideration on suppression of cancer cell proliferation by ultrasound exposure using sonochemical and biological measurements," J. Phys. Conf. Ser., vol. 1, pp. 210-215, 2004.

[8] J. Zimmerman, et al., "Cancer cell proliferation is inhibited by specific modulation frequencies," Br. J. Cancer, vol. 106, no. 2, pp. 307-313, 2012.

[9] T. M. Louw, G. Budhiraja, H. J. Viljoen, and A. Subramanian, "Mechanotransduction of ultrasound is frequency dependent below the cavitation threshold," Ultrasound Med. Biol., vol. 39, no. 7, pp. 1303-1319, July 2013.

[10] M. Ivone, C. Pappalettere, A. Watanabe, and K. Tachibana, "Study of cellular response induced by low intensity ultrasound frequency sweep pattern on myelomonocytic lymphoma U937 cells," J. Ultrasound, vol. 19, no. 3, pp. 167-174, September 2016.

[11] L. B. Feril, Y. Irie, K. Ogawa, I. G. Solano, K. Tachibana, and K. Yamaguchi, "Therapeutic potential of low-intensity ultrasound (part 1): Thermal and sonomechanical effects," J. Med. Ultrasonics, vol. 35, pp. 153-160, December 2008.

[12] B. Krasovitskia, V. Frenkelbn, S. Shohama, and E. Kimmela, "Intramembrane cavitation as a unifying mechanism for ultrasound-induced bioeffects," in Proc. Natl. Acad. Sci. USA, 2011, vol. 108, pp. 3258-3263.

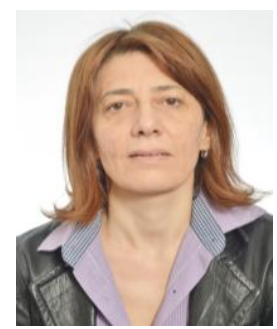

Mariantonietta Ivone graduated in Mechanical Engineering at the Politecnico di Bari in a.y. 1996. Her master degree thesis arranged at Notthingam University was about "Braided materials mechanical characteristic". In April 22, 2016 she obtained the Doctorate in Mechanical Engineering at the Politecnico di Bari with the thesis "Acoustic methods for diagnosis and treatment at cellular level" under supervision of professor Carmine Pappalettere. During doctorate she had opportunity to work with an eminent scientist like professor Katsuro Tachibana at Fukuoka University (Japan). There the effect of mechanical loads, due to ultrasound, on leukemic cells was investigated for different sonication conditions. After in Dundee University (Scotland) under the supervision of professor Paul Campbell human breast adenocarcinoma cell line viability and stiffness were evaluated.

She began her professional activity like installations and structures free lancer planner at family enterprising activity, after she worked like mechanical engineer in some factories and at this time she became Mechanical disciplines tenured teacher in public high school.

Today she is a mathematic and physic tenured teacher at the scientific high school of her city (Liceo Scientifico Majorana, Putignano), but she is keeping to work about her research interest. She is interested to understand the relationships between cell mechanical property and cancer phenotype, as it could be very useful for a cancer noninvasive therapy. Her main papers are:

M. Ivone, C. Pappalettere, A. Watanabe, and K. Tachibana, "Study of cellular response induced by low intensity ultrasound frequency sweep pattern on myelomonocytic lymphoma U937 cells," $J$. Ultrasound, vol. 19, no. 3, pp. 167-174, 2016.

M. Ivone, C. Pappalettere, and K. Tachibana, "Study of cellular response induced by frequency change of low intensity ultrasound," in Proc. E-Health and Bioengineering Conference, Iasi, 2015. 